\title{
'Walkabout Tourism': Is there an Indigenous Tourism Market in Outback Australia?
}

\author{
By Andrew Taylor \\ Dean Carson ${ }^{\dagger}$ \\ Doris Carson
}

\begin{abstract}
Outback areas of Australia account for much of the landmass with just 5\% of the population, many of whom are Indigenous Australians. Despite tourism being an important industry for Outback economies, it has declined in recent decades prompting a search for new and expanding tourism markets. While Indigenous tourism in the form of visits to Indigenous communities, attractions and sites to obtain the Indigenous 'experience' has been pursued it has, along with other niche markets, delivered at best limited and isolated successes. But Indigenous people are themselves highly mobile, making frequent and regular trips away from home. In the past these trips were labelled in a derogatory way as 'walkabout'. The characteristics of these trips posit them firmly within accepted definitions of tourism but, excepting one study on homelessness, there is a vacuum in research on the potential of people 'on the move' as a tourist market. Consequently, we do not know the potential size or characteristics of the market, an awkward contradiction given the historical focus on generating tourism at places where Indigenous people live. This study is the first to analyse data for Outback areas from the perspective of providing baseline information about that market. While results are mixed in terms of the potential to support a flailing tourism industry, this study finds that Indigenous people on the move should not be ignored.
\end{abstract}

\section{Background and Introduction}

The Australian landmass is the size of continental United States (excluding Alaska) but has a population of just 23 million. These are concentrated in and around large cities like Sydney, Melbourne and Brisbane along the eastern coastline, their hinterlands and in the rapidly growing city of Perth in the far west of the country. By 2012 some $80 \%$ and growing of the nation's population resided in these urban and peri-urban areas (ABS, 2012a). Away

\footnotetext{
${ }^{*}$ Senior Research Fellow, Charles Darwin University, Australia.

†Professor, Charles Darwin University, Australia.

${ }^{\sharp}$ Independent Scholar, Charles Darwin University, Australia.
} 
from the eastern coastal strip the population density falls dramatically to around 1 person per square kilometre. These 'Outback' areas constitute more than three quarters of the Australian landmass but are home to less than 5\% of its residents. There are high proportions of Indigenous Australians (Aboriginal and Torres Strait Islander people) resident, contributing up to $90 \%$ of the population in some areas (Figure 1).

Figure 1. The Distribution Of Australia's Indigenous People

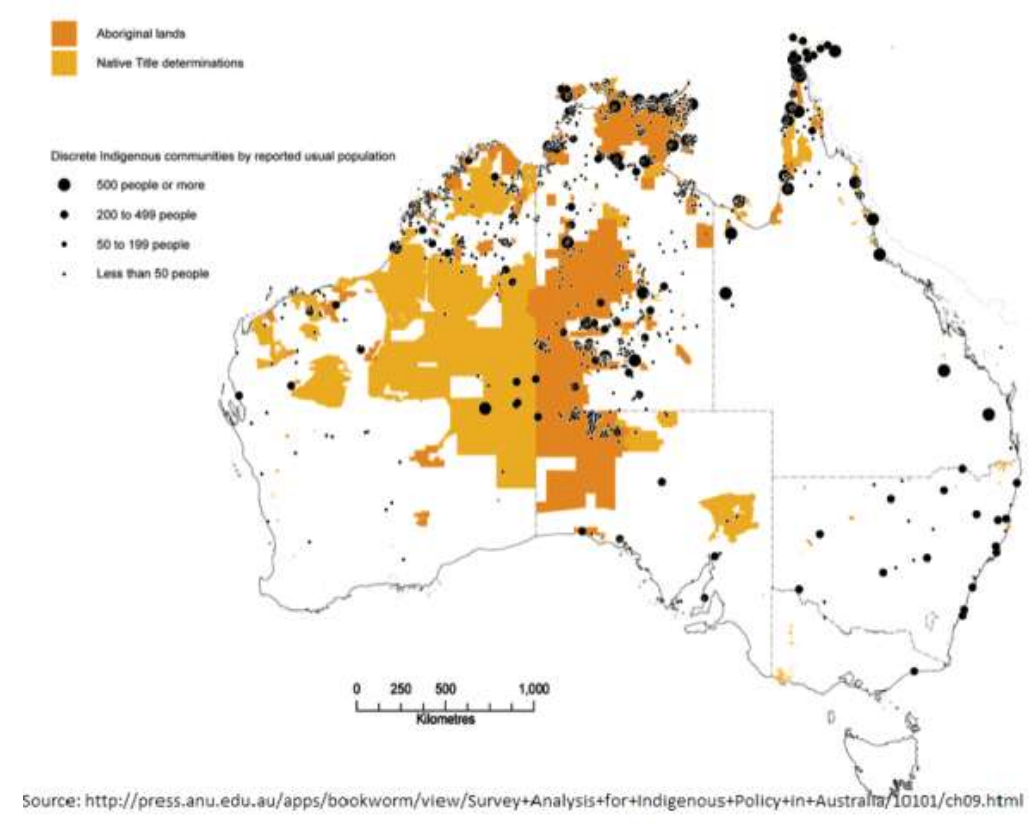

Tourism activity, a major contributor to the national economy, is urban and likewise peri-urban centric and its economic contributions likewise (Taylor and Carson DB, 2010). Despite tourism also being an important industry for many Outback regions, visitation and economic attribution have progressively declined since 1990 (Schmallegger et al., 2011). A number of studies and indicators support this claim (for example, Carson DB et al., 2009; Schmallegger \& Carson DB, 2010; TRA, 2010) and, importantly, the extent of decline for individual regions appears to have been positively related to the degree of remoteness. Particularly gloomy observations have been made about regions which market themselves as part of the Australian 'Outback' (Carson DB \& Taylor, 2009).

Despite recent growth experienced in Outback areas from extractive industry projects (such as mining and LNG gas developments), net benefits for local communities, such as rent transfer have been underwhelming. This is often in contradiction to what is touted by political and industry sources at the beginning of projects (Rolfe \& Kinnear, 2013; Taylor and Carson DB, 2014). This contemporary economic landscape has triggered structural adjustments towards higher concentrations of jobs in services (especially health, education and justice services) and associated reductions in private sector and small business employment. In parallel, the entrepreneurial and innovative capacity 
of Outback areas has seemingly been diminished (Carson DB, 2011; Carson DB \& Carson DA, 2013).

Although a diverse set of transitions have occurred across regions, reductions in the key markets of backpackers, organised coach tours and selfdrive markets have resulted throughout the Outback (Schmallegger et al., 2010). In tandem with 20\% declines in total visitor numbers between 1999 and 2009 (Schmallegger \& Carson DB, 2010), record numbers of Australians have travelled overseas each year. With domestic visitors accounting for two-thirds of Outback itineraries, the latter has been a critical issue. Only one or two regions within the Outback have avoided these sorts of declines and, ironically, one of these is Australia's North West which is focused on coastal tourism activities like whale watching. It is also the only region not to have the word 'Outback' in its title (Carson DB \& Taylor, 2009).

Flailing Outback tourism has prompted national, State and Territory organisations responsible for its development, as well as organisations with a specific Outback remit (regional and local tourism organisations and regional development networks), to proffer and advance alternative markets and activities, such as heritage (Carson et al. 2009), four wheel drive (Taylor \& Prideaux, 2008), wildlife (Carson DB \& Schmallegger, 2009), fossicking and farm or station tourism (Taylor \& Carson DB, 2007). However, stark assessments about levels of success towards diversification can be found. Schmallegger and Carson's (2010) study, for example, points to institutional and developmental 'lock in' as a key stumbling block for diversification and growth. Consequently, periods of improvements for tourism at the national level subsequent to the Global Financial Crisis have not been replicated for individual Outback regions (Carson DB \& Carson DA, 2014).

One market which has been pursued strongly in recent decades for its potential to redress declines in Outback tourism is the Indigenous tourism market (Whitford \& Ruhanen, 2009). Indigenous tourism in this context refers to non-Indigenous visits to Indigenous communities, to sites of cultural significance, and also to engagement with Indigenous people in tours or to view and purchase arts or crafts. The belief that Indigenous tourism is and can be an important market has been evident in the nomenclature of marketing and product campaigns from the national, state and regional tourism bodies (see Carson DB \& Taylor, 2009). A unique point of difference is the rich and unique stock of cultural attractions and assets, albeit spread over vast distances and accompanied by limited or no tourism infrastructure. Indigenous tourism has also been promoted in planning and governance strategies associated with the organisations charged with tourism product and marketing development including the national body, Tourism Australia. That organisation in particular has long embedded images of Indigenous people and attractions into its international campaigns as evidence of opportunities for Outback visitors to access a spiritual or cultural experience there (Carson DB \& Taylor, 2009; Schmallegger et al., 2011; Pomering, 2013).

Nonetheless, a swathe of complex and interrelated issues for the supply of Indigenous tourism products, infrastructure and services in Outback areas are 
documented (Buultjens \& Fuller, 2007; Tremblay, 2009 \& 20010). Similarly, there are demand side constraints with expenditure on Indigenous tours, shows, arts or crafts constituting a very small part of the overall Outback expenditure by visitors and with Indigenous experiences receiving low priority on Outback itineraries (Schmallegger, \& Carson, DB, 2007; Taylor \& Carson DB, 2010). With visitor numbers, expenditure, nights and activities in Outback areas at historical low points, and repeat visits uncommon, such difficulties have proven indomitable with only isolated pockets of long-term success in the establishment and sustainment of Indigenous tourism businesses in the Outback documented (Buultjens \& Fuller, 2007; Carson DB \& Taylor, 2009).

Given the deflated environment for tourism in Outback areas, it is anachronistic that Outback Indigenous residents, estimated at 120,000 (Van Caenegem et al., 2014) and known to undertake regular and frequent shortterm trips away from home, have not been considered or discussed for their potential as a tourist market. The mobility of Indigenous people in the Outback is well documented (Taylor and Carson, 2009). Historically, such movements were met with derision from officious bodies and those charged with the assimilation of First Australians. A lack of understanding on the directions, purpose, length and activities undertaken on trips has permeated through history in Australia and to this day creates friction between residents and those 'on the move'. This lack of understanding and empathy led to the term 'walkabout' being adopted colloquially to denote the seemingly unexplainable and unplanned nature of trips (Petersen, 2004).

In recent times, knowledge about Indigenous mobility (as it is known in academic literature) in Outback areas has been greatly improved thanks to studies in anthropology, migration studies and the analysis of the demand and supply of services like housing, health and education. Despite this, visitors from Outback areas have commonly been labelled 'transients' or 'itinerants', and their travel patterns have been described as falling within one of three categories: 'sacred' travel (people travelling to fulfil obligations to kin, culture and traditional land), service-related travel (people travelling to access health and social services), or travel perceived as a social problem (people travelling to access non-sacred entertainment including access to alcohol and gambling) (Carson et al., 2013).

Substantial gaps remain in relation to understanding about the numbers of people on the move, their sources and destinations, and their characteristics. This is largely because official data collections have limited capacity to accurately and comprehensively account for people on the move (Taylor, 2011). A further reason has been the inability for the research community to move away from problematizing Indigenous people on the move and equally in distinguishing trips as invariably being culturally motivated (to attend cultural ceremonies and so on) (Taylor \& Carson DB, 2009). Trips from Outback Indigenous communities have long been seen by residents and officials elsewhere as problematic (like anti-social behaviour) and creative of friction (Carson et al., 2013). The underlying, generalised and subtly discriminatory 
view is Outback Indigenous residents 'belong' in the Outback and not in towns or cities creating problems.

A recent attempt to conceptualise Indigenous travellers as tourists was made by Carson et al. (2013) in the Annals of Tourism Research. Their study was on Indigenous itinerant visitors (or 'long grassers') to the city of Darwin in the Northern Territory. They examined travel patterns and some characteristics of trips and contested that, under any accepted definition, longrassers were tourists. As such, they reasoned that attempts to manage friction between these and Darwin residents would benefit by perceiving long grassers as 'problem tourists' who:

'...are incompatible with the accepted dominant status of tourism and emerge from social distance between tourists and hosts, or between different groups of tourists.' (p.1)

The longrassers study focused on only a small part of Outback Australia and did not overtly examine the potential of visitors as a tourism market. The present study is the first to provide baseline data and information on Indigenous people in Australia as tourists, with a focus on Outback areas. We indicate the size and composition of the market by calculating numbers of Indigenous people who were away from home throughout Australia on the night of the Census of Population and Housing in August 2011. We outline the relationships between being on the move and demographic, socio-economic and other characteristics. We then examine the flows of people (by source and destination) as representative of itineraries to discuss the possible net contributions of 'the market' for Outback Australia.

\section{Methods}

Each five years, the Australian Bureau of Statistics undertakes the national Census of Population and Housing, which is designed to collect demographic and socio-economic data from all people in Australia on a specific night (in early August). Australian residents provide their location on Census night as well as the address they consider to be their place of usual residence. Downstream coding processes enable users of the data to construct custom matrixes to identify people away from home on Census night, their characteristics and their usual place of residence. The comparison of the two locations (place on Census night compared to place of usual residence) enabled us to construct tables on Indigenous people on the move.

The geographical basis for our study was to compare and contrast the size of the Indigenous cohort on the move in the Outback with the rest of Australia and with non-Indigenous people. Regions were 'constructed' from smaller statistical regions (called Statistical Area Level 3) to enable the Outback to be constructed as one region as well as to facilitate comparisons across geographic levels. In deriving analysis for the size and direction of movements between 
Outback and other areas, we divided Australia up into three geographic regions: Outback areas, Capital Cities and Metropolitan Hinterlands. For a number of reasons, including the tendency for many people to not state or partially state where they live and where they were on Census night, the data on flows might be seen as indicative with the value of flows analysis being in proportional comparisons on the size and directions of flows rather than in outlining absolute numbers.

There are some limitations with using Census data to assess the size and characteristics of the Indigenous tourist market in Outback Australia. Not least, the Census is a snapshot held on one night and conducted in early August which, in the north of Australia, is the 'dry' season and allows for relative ease of movement since river and creek crossings on roads are not impassable. Because some people in the Census leave the question on Indigenous status as 'not stated' we allocated these according to stated responses (as standard practice in the use of such data). In addition, the Census cannot report on trip characteristics like purpose, length and travel parties. Nonetheless, there is sufficient congruence in the existing literature to extrapolate from the results in this study on the potential of the market according the known facets of trips in Outback areas. This study is, therefore, baseline by nature in assessing the size and composition of the market and on that basis provides a platform on which future research activities can be based.

\section{Results}

\section{Market Size and Characteristics}

Indigenous people made up $2.7 \%$ of the Australian population in 2011 but in Outback areas this was $23 \%$ (141,289 people). Nationally, some 42,500 $(7.4 \%)$ Indigenous people were away from home on Census night, compared to $4.7 \%(875,000)$ of the non-Indigenous population (Table 1). In Outback areas, home to 586,000 people in total, a greater proportion of both Indigenous (8\%) and non-Indigenous (7\%) residents were away from home. Consequently, around $27 \%(10,700)$ of all people who were away from home in Outback areas were Indigenous.

Table 1. Summary of Population and Indicators of People 'On the Move'

\begin{tabular}{|l|c|c|c|}
\hline \multicolumn{1}{|c|}{ Summary indicator } & Indigenous & Non-Indigenous & Total \\
\hline Proportion of the Australian population & $2.7 \%$ & $97.3 \%$ & $100.0 \%$ \\
\hline Proportion of the Outback population & $24.1 \%$ & $75.9 \%$ & $100.0 \%$ \\
\hline Proportion of those living in Outback areas & $24.5 \%$ & $2.1 \%$ & $2.8 \% *$ \\
\hline Away from home - Outback areas & $8.4 \%$ & $7.4 \%$ & $7.6 \%$ \\
\hline Away from home - Australia & $7.4 \%$ & $4.7 \%$ & $4.8 \%$ \\
\hline Proportion of all people away - Outback areas & $26.7 \%$ & $73.3 \%$ & $100.0 \%$ \\
\hline Proportion of all people away - Australia & $4.1 \%$ & $95.9 \%$ & $100.0 \%$ \\
\hline
\end{tabular}

*Denotes the proportion of the national population living in outback areas 
Despite an over-representation of Indigenous people amongst those on the move in Outback areas, there was no correlation between the proportion of the population at the individual region level which was Indigenous and the proportion on the move (Figure 2). Even in regions with a very high Indigenous representation in the resident population, people were no more likely to be on the move. Indeed, three of the top five regions for Indigenous composition (the Far North of Queensland and East Arnhem and Daly-TiwiWest Arnhem regions in the Northern Territory) had below average proportions of Indigenous people away from home on Census night.

Figure 2. Percent Indigenous Versus Precent away from Home, Outback Regions, 2011

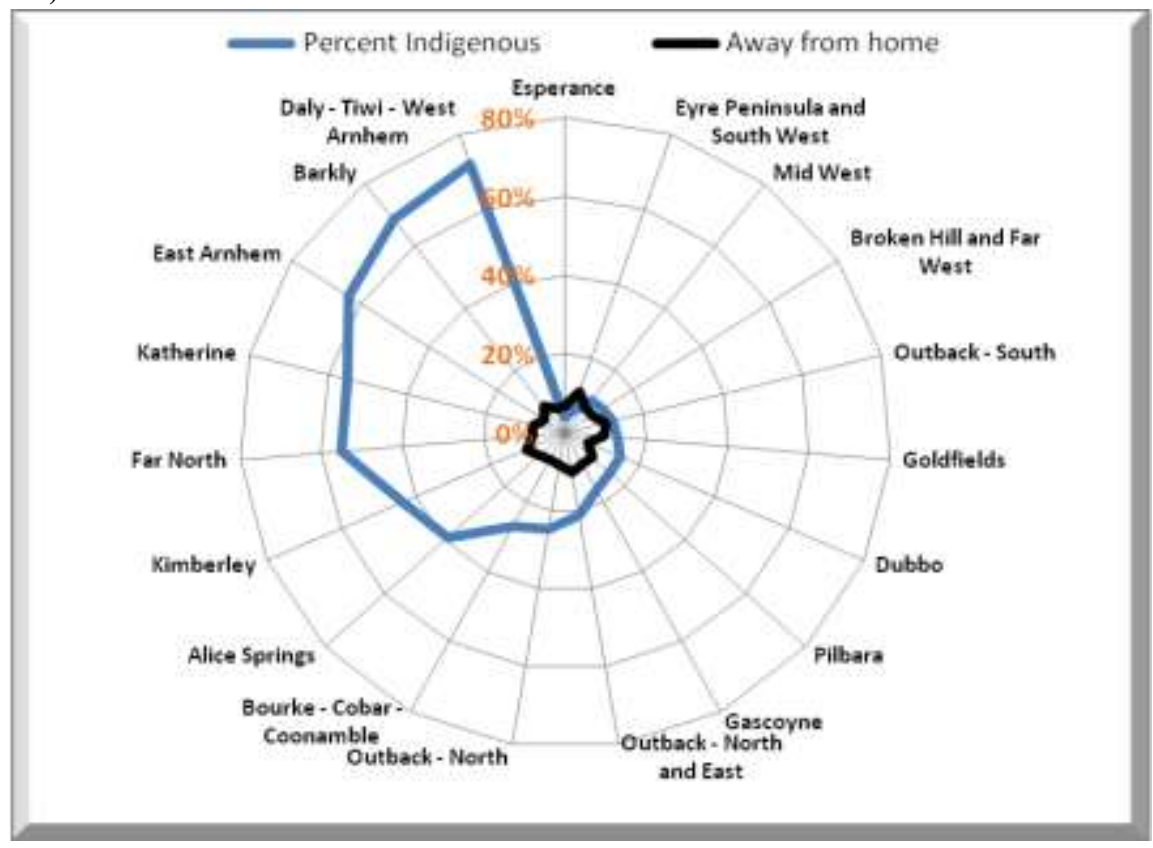

\section{Age and Gender Profiles}

Those aged 10-19 years and 20-29 years comprised more than $40 \%$ of Indigenous people away from home on Census night $(23 \%$ and $19 \%$ respectively). But the age profile of people on the move differed markedly by gender with males skewed towards younger age groups and the female distribution very consistent across all age groups at around 15\%. Indeed the direction of correlations for males and females between age and the probability of being away are opposite. For males, being away from home was negatively correlated to age $\left(\mathrm{r}^{2}=-0.78\right)$ while for females the correlation was positive $\left(\mathrm{r}^{2}=\right.$ $0.73)$.

Standardising by age and gender revealed additional perspectives with females on the move over-represented (compared to the proportion in the population) at ages 20-29 years and in the older age groups (Figure 3). Males aged 10-19 were particularly over-represented (or highly 'on the move'). Meanwhile the very young were substantially under-represented indicating a 
small share of people less than 9 years of age were away from home on Census night.

Figure 3. The Extent of Over or Under Representation for People Away from Home by Age and Gender, 2011

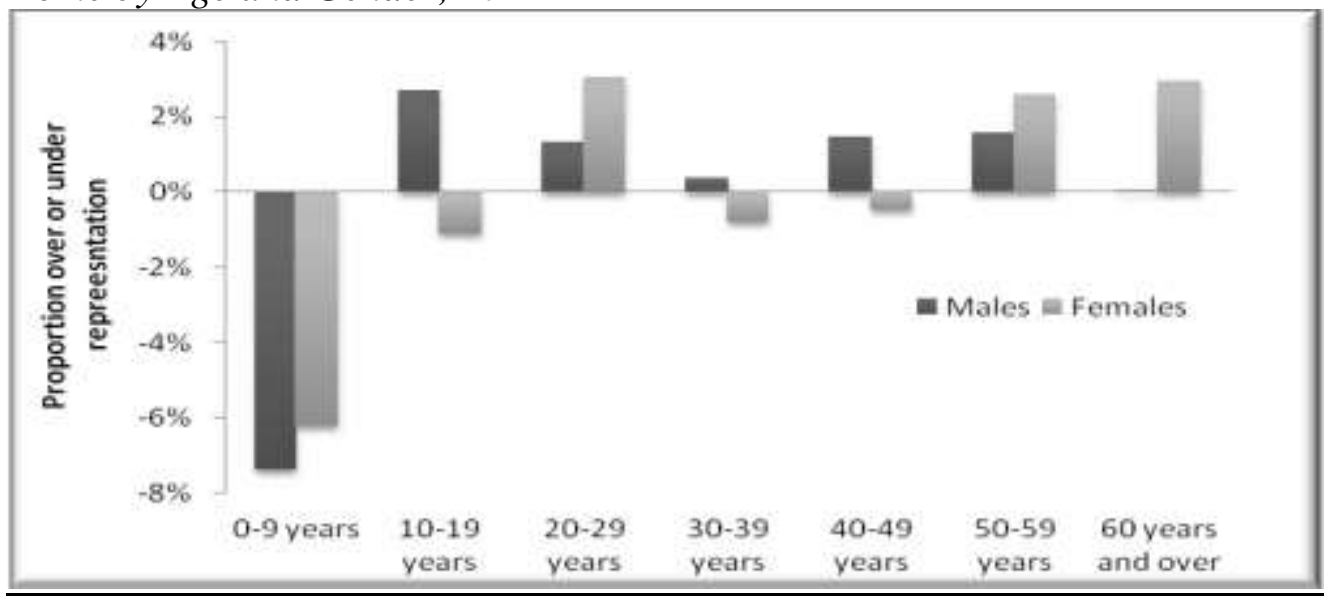

Other Socio Economic Indicators

Of those attending an educational institution, 9\% were away from home on Census night. Profiling by type of institution (Figure 4) shows people attending post-school institutions (Tertiary and Further Education, University and Other institutions) were far more likely to be on the move. A third of university attendees, for example, were away from home. This is largely expected given that there are almost no secondary institutions (with hard infrastructure), let alone tertiary institutions located at Outback Indigenous communities.

Figure 4. Type of Educational Institution Attending for Indigenous People Away from Home, 2011

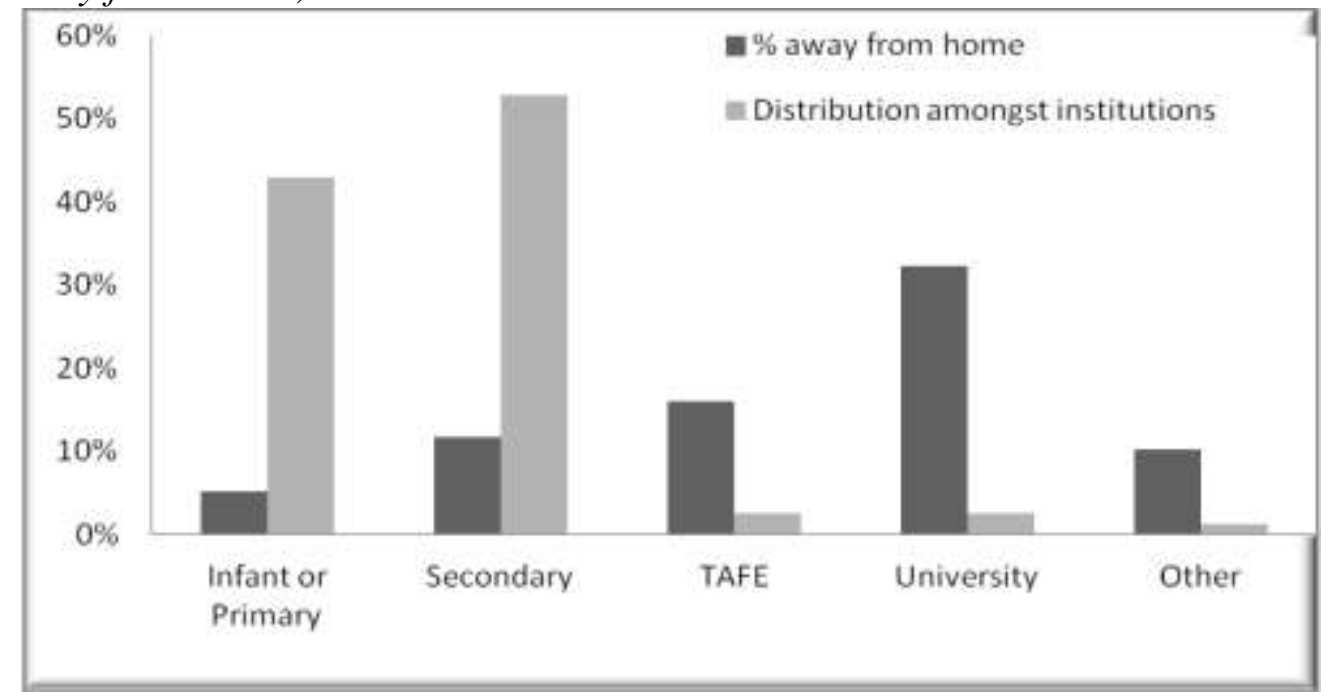

In terms of partnering status, those never married were most likely to be away from home and were over represented in that cohort when compared to 
the proportion in the overall population ( $8 \%$ for males and $6 \%$ for females). Divorced and separated people were also over-represented, however married people were less likely to be on the move. For labour force status, those employed or not in the labour force were highly under-represented in people away, while the unemployed and those who did not state their labour force status were slightly over-represented (Figure 5).

Figure 5. Labour Force Status and Being Away From Home, 2011

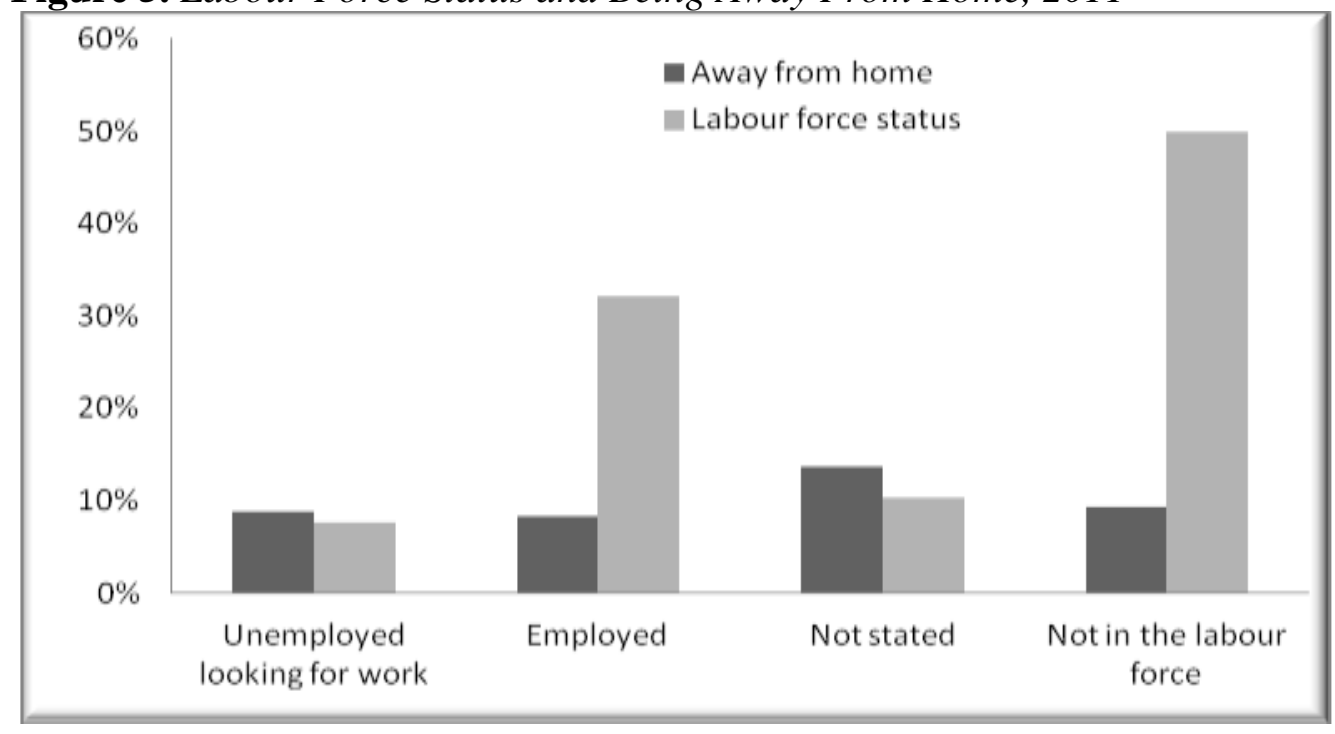

Comparing the distribution of people away from home to incomes shows that most Indigenous people residing in Outback areas had quite low incomes of below $\$ 30,000$ (Australian Dollars) per annum. However, a larger proportion of Indigenous people who were away from home were in higher income brackets of above $\$ 30,000$ (Figure 6).

Figure 6. Income and Being Away From Home, 2011

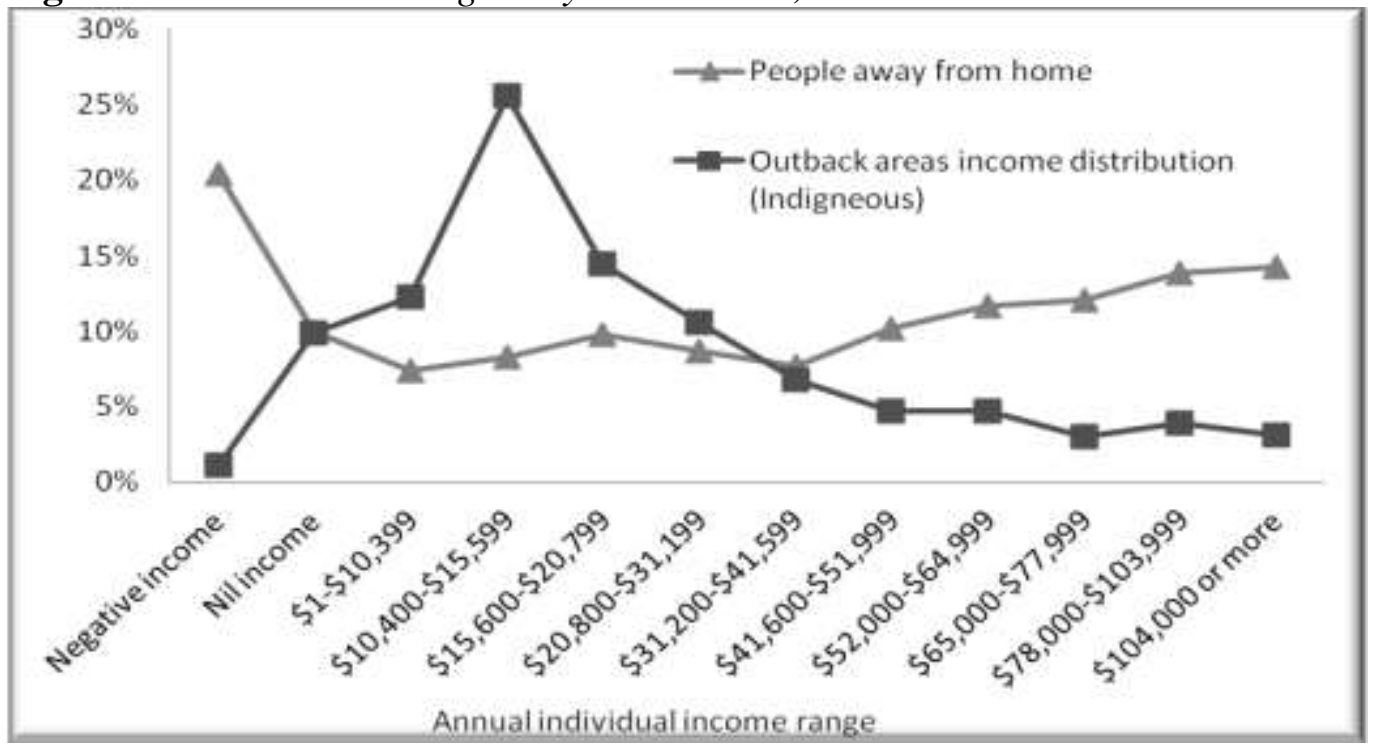




\section{Geographic Flows}

In 2011, over $95 \%$ of people away from home in Outback areas had left the immediate area in which they resided, although more males $(4.8 \%$ Indigenous and $2.6 \%$ non-Indigenous) remained within the same area compared to females (3.5\% and $2.1 \%$ respectively). Examining movements involving travel to, from or within Outback areas, $44 \%$ of people travelled into the Outback (i.e. from Capital Cities or Hinterlands), some $40 \%$ travelled out (i.e. to Capital Cities or Hinterlands) and $16 \%$ travelled within Outback areas.

Movements into the Outback were primarily from geographically proximate Hinterland areas $(60 \%)$ or Capital Cities $(40 \%)$. Interestingly, it was the reverse for movements out of Outback areas where most (57\%) were to Capital Cities. Movements into Outback areas from Capital Cities and Hinterlands were highly male biased at 157 males for every 100 females. However, more females than males (a ratio of 97 males per 100 females) travelled out from Outback areas.

\section{Discussion and Conclusions}

This research has revealed a number of important features about the size and potential of the market of Indigenous people on the move in Outback areas. On the surface, its size appears to be quite small at around 43,000 people in 2011. Clearly, many Indigenous people were not visitors to Outback areas, instead were visiting cities or hinterlands. Despite this, the numbers in this study represent a snapshot of just one night, and that the annualised size of the market is likely to be substantially greater. Furthermore, the Indigenous population of Australia is growing rapidly and at a pace far greater than the remainder of the population (see Taylor \& Bell, 2013). Growth is particularly noticeable in Capital Cities, and, under these circumstances; we can expect the market to grow in line with population growth. Thirdly, in 2011 the Census was shown to have under-enumerated (through people being 'missed' or avoiding the Census) the number of Indigenous people in Australia by 17\%, compared to $6 \%$ for non-Indigenous people (ABS, 2012). It is generally accepted that rates of under-enumeration are higher in Outback areas (Taylor, 2011) although precise data are not available. These factors mean that the size of the market is substantially greater than the numbers provided in this study.

Although it might be argued on the basis of the low incomes of Indigenous people that economic attribution from 'the market' in Outback destinations simply does not exist, there are mitigating factors to this line of argument. People on the move had relatively higher incomes, with older females (likely to have higher incomes because they are the most qualified) over-represented, while the very young (with very low incomes) were under-represented.

Furthermore, while Census data does not capture trip characteristics of length, expenditure and purpose for trip, studies in Outback areas have identified commonalities in key trip characteristics by Indigenous people. Invariably these are for combinations of trip purposes including visiting friends 
and relatives, health and leisure related (Carson et al, 2013; Habibis, 2011; Prout \& Yap, 2010). Length of trip is consistently denoted as high, and in many cases up to several months of duration (Morphy, 2007). Trips to and around Outback areas are said to be frequent, regular, and high in repeat visitation (Prout, 2008). The latter is in contrast to Outback trips by nonIndigenous people. Overall, therefore, trip attributes are positive in terms of market potential.

The flows data (which measures movement into and out of a location or area) provides interesting dichotomies regarding aggregated trip directions, gender compositions and the distribution of trips involving Outback areas. Firstly, almost all people on the move travelled to areas outside their area of residence. Given units of statistical geography in Outback areas are generally large this indicates many people were some considerable distance from home. Nevertheless, this finding must be tempered since, within larger Outback population centres, units of measurement are substantially smaller.

Flows data also suggests only a small portion of trips (16\%) were within Outback areas with trips to and from Capital Cities and Hinterlands comprising the majority. Furthermore, most trips to Outback areas were from Hinterlands while the majority of trips from the Outback were to Capital Cities. It is reasonable, therefore, to assume that some travellers are circulating from Outback areas to Capital Cities, on to Hinterlands and then returning to the Outback. Finally, the reverse gender bias for trips into and out of the Outback (with males dominating trips in, by some margin, and females marginally dominating trips out) indicates Outback areas are 'sending' females to capital cities while 'importing' male tourists from the Hinterlands. Both aspects of the flows data warrant further research at a more fine grained geographic scale.

From a theoretical perspective, the absence of studies on the Indigenous tourist market to date indicates a popularised tendency to view Indigenous people away from home as an anthropological phenomenon. In light of this study, broader conceptual and epistemological narratives are warranted. It is difficult to argue, for example, that women travelling to capital cities might be primarily seeking to fulfil cultural obligations. Examining the issue from a tourism market perspective is one alternative approach, although understanding Indigenous travel patterns from a tourism perspective would, however, require more primary data collection as existing tourist data sets (such as the national visitor survey conducted by Tourism Research Australia) do not include Indigenous tourists in the sample (or do not identify them as such).

This study has revealed the size and composition of the market suggests some potential, or at the very least, a need for further investigation into how potential might be developed. Given the small size of Outback communities, one or two sustainable jobs from tourism might make a large difference to people's lives. On balance, therefore, our study points to the potential for destinations to engage with and make gains from the market. Gains do not have to be direct financial transactions secured from travellers since providing services like an accommodation hub, in places where flows are concentrated, could attract infrastructure and grants, as well as assist in addressing 
homelessness or itinerancy issues. Consequently, a major part of the 'gains' to be had for destinations, is to re-envision Indigenous people on the move from one of problematisation to one of potential, thereby focusing on making all tourists feel welcome.

\section{References}

ABS (2012a) 1301.0 - Year Book Australia, 2012. Available at http://www.abs.gov.au [25 March 2014].

ABS (2012b) 2940.0 - Census of Population and Housing - Details of Undercount, 2011. Available at http://www.abs.gov.au [11 April 2014].

Buultjens, J. \& Fuller, D. (Eds) (2007). Striving for sustainability: case studies in Indigenous tourism. Lismore: Southern Cross University Press.

Carson, DB. \& Taylor, A. (2009). 'We'll all go down together: the marketing response of Australia's Outback destinations to recent declines in performance'. In Fyall A, Kozek M, Andreu L (Eds), Marketing Innovations for Sustainable Destinations, 189-202, Oxford: Goodfellow Publishers.

Carson, DB., Prideaux, B., Coghlan, A. \& Taylor, A. (2009). Heritage as a motivation for four-wheel-drive tourism in desert Australia. Journal of Heritage Tourism, 4(3), 217-225.

Carson, DB. \& Schmallegger, D. (2009) 'Fishing the 'big rivers' in Australia's Northern Territory: market diversification for the Daly River'. In B. Prideaux \& M. Cooper (Eds), River Tourism, 131-146, Oxfordshire, UK: CAB International.

Carson, DB. (2011). 'Political economy, demography and development in Australia's Northern Territory' Canadian Geographer, 55(2), 226-242.

Carson, DA., \& Carson, DB. (2011). 'Why tourism may not be everybody's business: the challenge of tradition in resource peripheries.' The Rangeland Journal, 33(4), 373-383.

Carson, DB., Carson, DA. \& Taylor, A. (2013). 'Indigenous Long Grassers: Itinerants or Problem Tourists?' Annals of Tourism Research, 42, 1-21.

Carson DB. \& Carson DA. (2013). 'Mobilising labour in remote 'boom' towns for economic diversification: the case of Tennant Creek, Australia' Inner Asia Studies in the Humanities, 2, 31-44.

Carson DB. \& Carson, DA. (2014). 'Local economies of mobility in sparsely populated areas: Cases from Australia's spine'. Available at http://www.science direct.com/science/article/pii/S0743016714000369 [12 12 April 2014].

Habibis, D. (2011). 'A framework for reimagining indigenous mobility and homelessness' Urban Policy and Research, 29(4), 401-414.

Morphy, F. (2007). 'Uncontained subjects: 'Population' and 'household' in remote Aboriginal Australia' Journal of Population Research, 24(2), 163-184.

Petersen, N. (2004). 'Myth of the Walkabout movement: Movement in the Aboriginal domain'. In J. Taylor and M. Bell (Eds) Population Mobility and Indigenous Peoples in Australasia and Northern America, 223-238, London: Routledge.

Pomering, A. (2013). 'Indigenous Identity in the Nation Brand: Tension and Inconsistency in a Nation's Tourism Advertising Campaigns' Corporate Reputation Review, 16, 66-79.

Prout, S. (2008). 'On the move? Indigenous Temporary mobility practices in Australia' CAEPR working paper No. 48/2008. Canberra: Centre for Aboriginal Economic Policy Research. 
Prout, S. \& Yap, M. (2010). 'Indigenous temporary mobilities and service delivery in regional service centres: A West Kimberley case study' CAEPR working paper no. 66. Canberra: Centre for Aboriginal Economic Policy Research. Available at http://caepr.anu.edu.au/Publications/P/2010WP66.php [26 January 2014]

Rolfe, J. \& Kinnear, S. (2013). 'Populating regional Australia: What are the impacts of non-resident labour force practices on demographic growth in resource regions?' Rural Society, 22(2), 125-137.

Schmallegger, D., \& Carson, D. (2007). 'Reaching the Independent Traveller: Product Distribution Issues for Aboriginal Tourism Enterprises in Remote Australia'. In M. Kefalaki \& G. T. Papanikos (Eds) Essays on Tourism Research. Proceedings of the $3^{\text {rd }}$ International Tourism Conference. Athens, Greece: Athens Institute for Education and Research.

Schmallegger D., Carson DB. (2010). 'Is tourism just another staple? A new perspective on tourism in remote regions' Current Issues in Tourism 13(3), 201221.

Schmallegger, D. (2011). 'Managing the transition from coach- to car-based markets: the search for commercial value in Australia's Flinders Ranges' In B. Prideaux B \& DB. Carson (Eds) Drive tourism - Trends and Emerging Markets, 14-35, Milton Park: Routledge.

Schmallegger, D., Taylor, A. \& Carson, DB. (2011). 'Rejuvenating Outback Tourism through Market Diversification: the Case of the Flinders Ranges in South Australia' International Journal of Tourism Research, 13(4), 384-399.

Taylor, A. \& Carson, DB. (2007). 'Economic Development for Remote Communities - Can 4WD Tourism Help?' In M. Kefalaki and G. Papanikos (Eds). Essays on Tourism Research, 133-146, Athens: ATINER.

Taylor, A. \& Prideaux, B. (2008). 'Profiling Four Wheel Drive Tourism Markets for Desert Australia', Journal of Vacation Marketing, 14, 71-86.

Taylor, A. \& Carson, DB. (2009). 'Indigenous mobility and the Northern Territory Emergency Response' People and Place, 17(1), 29-38.

Taylor, A. \& Carson, DB. (2010). 'Four wheel drive tourism and economic development opportunities for remote areas' Tourismos, 5(2), 69-85.

Taylor, A., Bell, L., Axelsson, P. \& Barnes, T. (2011). 'The challenge of enumeration and population estimation in remote areas' In DB. Carson, R. Rasmussen, P. Ensign, L. Huskey \& A. Taylor (Eds), Demography at the Edge: Remote human populations in developed nations, 21-38, Farnham: Ashgate Publishing.

Taylor, A. \& Bell, L. (2013). 'The Northern Territory's Declining Share of Australia's Indigenous population: A call for a research agenda' Available at http://www. cdu.edu.au/the-northern-institute/research-brief-series [12 March 2014).

Taylor, A. \& Carson, DB. (2014). 'It's raining men in Darwin: Gendered effects from the construction of major oil and gas projects' Journal of Rural and Community Development, 9(1), 24-40.

Tourism Research Australia (2010). 'National and International Visitor Data' CD Mota online. Available at http://traonline.australia.com [22 July 2010].

Tremblay, P. (2009). 'The contribution of Aboriginal tourism to economic development: making appropriate distinctions' In J. Carlsen, M. Hughes, K. Holmes \& R. Jones (Eds), See Change: Tourism and Hospitality in a Dynamic World, 951-976, Fremantle: Curtin University of Technology.

Tremblay, P. (2010). 'Assessing the readiness of Aboriginal groups to participate in regional tourism development: A capabilities-based framework' Gold Coast: Sustainable Tourism Cooperative Research Centre. 
Van Caenegem, W., Cleary, J. \& Drahos, P. (2014). 'Pride and Profit: Geographical Indications as Regional Development Tools in Australia' Journal of Economic and Social Policy, Available at http://epubs.scu.edu.au/jesp [20 April 2014]

Whitford, M. \& Ruhanen, L. (2009) 'Indigenous tourism businesses in Queensland: Criteria for success. Gold Coast: Sustainable Tourism CRC. 